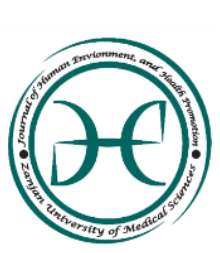

Journal of Human, Environment, and Health Promotion

Journal homepage: www.zums.ac.ir/jhehp

\title{
Prevalence of Hyperactivity in Elementary School Children in Saghez City, 2012
}

\author{
Hossein Masoomi Jahandizi ${ }^{\mathrm{a},}$, , Seyed Sahar Sheikh Ahmadi ${ }^{\mathrm{a}}$ \\ ${ }^{a}$ Department of Public Health, School of Public Health, Zanjan University of Medical Sciences.
}

*Corresponding author.E-mail address: hmjfh@ zums.ac.ir

\author{
A R T I C L E I N F O \\ Article history: \\ Received October 10, 2015 \\ Accepted November 28, 2015 \\ Article Type: \\ Original Article \\ DOI: 10.29252/jhehp.1.1.5
}

\section{Keywords:}

Attention Deficit and

Hyperactivity Disorder

Prevalence

Elementary School Children

Saghez City

\begin{abstract}
A B S T R A C T
Background: Attention deficit and hyperactivity disorder is a common disorder that causes serious problems in elementary school and it is also implicated in crime statistics, aggression and other behavioral problems in society. This study estimated the prevalence of hyperactivity in elementary school children in Saghez City, Iran, at the age of $6-11$ years.

Methods: In this study, 760 students were selected from elementary school boys and girls equally, from Saghez. A type of cross-sectional multi-stage random sampling method was used, and from the elementary school student's academic year, 12 to 2011 were selected. First, variables such as; age, gender, grade level, school status, Children age, employment, parents' level of education, family size, child's birth order, and parental psychiatric history were collected. Second, the teacher and parent questionnaire, "ADHD rating scale-IV," which consisted of two parts, was used. For the data collection, a copy of the letter was given to the teacher to complete and the questionnaires delivered. After completion, collected data was analyzed using the SPSS, 11.5 software.

Results: The results showed that the prevalence of ADHD in the children was $34.4 \%$, and by gender: girls $34.2 \%$ and boys $34.6 \%$. Higher numbers of hyperactivity disorders were found in families whose parents had lower levels of education. Hyperactivity was observed to be higher in the third and fourth children who were born into larger families, but there was no significant correlation found between the prevalence of hyperactivity and the number of family members $(\mathrm{p}=0.16)$.

Conclusion: The results of this study indicate that the development of training programs for disease prevention and managing hyperactivity disorder, in families with low socio-economic should be a priority.
\end{abstract}

\section{Introduction}

Hyperactivity disorder is a neurological development disorder with three main characteristics of attention deficit hyperactivity and impulse control [1]. Attention deficit and hyperactivity disorder (ADHD) is the most common and well known psychiatric problems among children and

To cite: Masoomi Jahandizi H, Sheikh Ahmadi SS. Prevalence of Hyperactivity in Elementary School Children in Saghez City, 2012. J Hum Environ Health Promot. 2015; 1(1): 34-40. 
adolescents in schools. This disorder is defined as having a "stable pattern of behavior and attention deficit hyperactive impulse" than the age at which children are usually seen with the same maturity level, is intense. To diagnose this disorder, a number of symptoms must appear before the age of 7 years, but after that age the disorder usually causes behavior problems in schools and in other places which leads to children being diagnosed [2]. Research results have shown that the brains of children with this disorder are different. For example, the performance of these children's brains when focused on attention and alertness demonstrate that the Brain network is not working properly. The cerebellum and the frontal lobe which hold the basic functions of planning, organizing, decision making, perception and thinking, have impaired inhibition time in these children [2]. Health and disease in children will affect tomorrow's society and future generations. Therefore, the study of mental health and children's adjustment in adulthood will contribute to improvements in society, while a lack of attention to the development of childhood mental health issues could inflict irreparable damage [3]. Attention deficit hyperactivity problems in children and adolescents, are the most common cause of referral to a psychiatrist or consultant pediatric. The disorder also has a profound impact on the lives of thousands of children and their families [4].

ADHD is a behavioral pattern that occurs in childhood and results in the development of a disproportionate amount of attention, impulsive and other problematic behaviors [5]. Although in previous years, there was the mistaken belief that the disorder improved after the teenage years, it is now obvious that this disorder continues into adulthood in more than $50 \%$ to $70 \%$ of cases [6]. Onset before the age of 5 or 7 years makes it difficult to determine the age for this disorder, however, research findings have shown that it is sometimes possible. The criteria are normally applied to determine the disorder after the age of 7 years [6]. There are three times as many boys as girls affected by this disorder. The disorder causes problems in many different fields of education, including; poor academic performance, grade repetition, school leaving, poor family relationships and friendships, anxiety, depression, abuse, aggression, drug abuse at an early age, and it is also associated with high numbers of people who break the law [4]. These children also have increased levels of associated disorders: conduct disorder, antisocial personality disorder, and conversion disorder, substance abuse and anxiety disorder, can be seen in subsequent years [6]. Moreover, it has been shown that around two thirds of the children's symptoms are still apparent in later years [6].

At present, the best course of action to prevent further complications and difficulties, including disorders in later mental development, physical injuries, and even substance abuse, is early diagnosis and treatment of ADHD. However, in regard to general and detailed information there is not a lot of information available.

Epidemiological studies on the prevalence of the disease and the factors that can help to improve clinical decision making have been conducted [6]. Studies have shown a high prevalence of hyperactivity disorder, and it has been demonstrated that early diagnosis and treatment is important. The prevalence of ADHD in Iranian children aged 7 to 12 years has been reported to be approximately $3 \%$ to $6 \%$ of the population [5]. Moreover, $33 \%$ of patients referred to occupational therapy centers account for this disorder [6].

Worldwide, the prevalence of this disorder has been reported to be $3 \%$ to $8 \%$ [7]. Given the importance of the subject, the varying 
results of different studies, the lack of specific studies on this problem, and the significant problems present in Saghez City which were creating problems in a number of areas of family life, we decided to investigate the prevalence of this disorder in young students living in Saghez.

\section{Materials and Methods}

This was a cross-sectional study. The populations of all primary schools in Saghez city were included. After obtaining the necessary permission from the Department of Education of Saghez, samples of elementary school students (except special education schools) were selected during the academic year from 2010 to 2011 using a multi-stage sampling technique. To calculate the sample size, taking into consideration of the prevalence of hyperactivity at 5\%, 95\% confidence level, and error level 0.3P, using the formula $\mathrm{N}=\mathrm{z}^{2} \mathrm{pq} / \mathrm{d}^{2}$, a final sample of 760 was calculated. To create a representative sample, in terms of the socio-economic status of the three regions, clusters were selected. These were then divided into districts: uptown, downtown, central and periphery of the city. Then, in each region, a girls' school and a boys' school were randomly selected from each grade in each school (5th grade).

So every school in the fifth grade was grade 5. In classrooms with an average of 30 students, all students were investigated.

Data was gathered by a questionnaire consisting of two parts. First variables such as; age, sex, education, child's education, parental age, parental education, parental occupation, family size, birth order in the family, parental psychiatric history, and in the second part, teacher and parent questionnaires entitled, "ADHD rating scaleIV", which is known to be a standardized questionnaire with demonstrated reliability and validity, was used. Teachers were asked to gather information and to complete a copy of the letter that was provided.

A teacher and parent questionnaire "ADHD Rating scale-IV" for the options: never, sometimes, often and very often the case, were graded 3 - 2- 1 or 0 , respectively. Based on the interpretation of the test table, after collecting questionnaire-based information, and then the students with attention deficit disorder/hyperactivity were selected. For example, if the questionnaire scores were equal to or less than 13 subjects, and if the score was higher than 13 , students were considered to have ADHD.

For data analysis, simple descriptive statistics were used in this study. Each student questionnaire included characteristics such as; gender, education, family size, child's rank in the family, parental age, parental occupation and further information about the level of education that included the 18 ADHD symptoms which were assigned. The symptoms of an overactive 4-option response were titled A: Never, B: Sometimes, C: Most and D: often. A total of 18 marks were possible to answer the question, zero points were given if the answer was Option $\mathrm{A}$, and two points were awarded if the answer was option $\mathrm{B}$ and if the answer was $\mathrm{C}$ it received three points. And if the answer was D it received four points. The final marks of all the questions (18 marks hyperactivity) were added together. If the score is 13-0 in healthy children, then the rates in the more active students were raised to over 13.Data was collected using SPSS statistical software version 11.5 and descriptive statistics, chi square analyzes were used. The level of significance was set at 0.05 .

\section{Results}

Results of this study showed that the prevalence of ADHD was 4\% (34 children) (Table 1). Given that there were an equal 
number of boys and girls participating in the study there were approximately equal percentages of males and females (girls $49.9 \%$, boys $50.1 \%$ ). The number of participating students with ADHD in grades; first, second, third, fourth and fifth grade were also almost equal. The findings showed that most students (49\%) were a first child and only a small number of students $(9 \%)$ were the fourth in the family. Education levels; illiterate parents $59(5 \%)$, elementary and secondary school $13.5 \%$ of them also had a college education. $74 \%$ of illiterate parents in the education of elementary and secondary school have a small percentage of them $(6.9 \%)$ had a college education. father's job was open $49 \%$ of students, $27 \%$ are other workers. Job more students $(91.8 \%)$ was housewives $7.4 \%$ unemployed. The students $87.3 \%$ and $7 \%$ of the families of $5-3$ persons in families with one or two people lived. The average age of the student's mothers was 34.72. Hyperactivity disorder in both sexes was almost equal (girls $34.2 \%$ and boys $34.6 \%$ ). Chi-square test shows a significant correlation between the prevalence of ADHD children, $(p=0.49)$ in Table 2.

The findings suggest that hyperactivity disorder is roughly equal in both sexes (girls $34.2 \%$ and boys $34.6 \%$ ). Chi-square test showed a significant correlation between the prevalence of ADHD children and sex $(p=$ 0.49). According to Table 3, grade two $(43.7 \%)$, and grade four students $(37.5 \%)$, had more hyperactivity disorder than other grades. Chi-square test showed a significant correlation exists between the prevalence of hyperactivity and grade $(p=0.035)$.

Table 1: The Relative Frequency Distribution Table Hyperactivity Disorder in the Saghez City.

\begin{tabular}{ccc}
\hline Hyperactivity & Number & Percent \\
\hline Yes & 259 & $34.4 \%$ \\
No & 494 & $65.6 \%$ \\
\hline Total & 760 & $100 \%$ \\
\hline
\end{tabular}

Table 2: Relative Frequency Distribution Hyperactivity in Children on the Basis of Sex in the Saghez city.

\begin{tabular}{ccccc}
\hline \multirow{2}{*}{ Hyperactivity } & \multicolumn{3}{c}{ Sex } \\
\cline { 2 - 5 } & Gumber & percent & Number & percent \\
\cline { 2 - 5 } NO & 246 & $65.8 \%$ & 246 & $65.4 \%$ \\
Yes & 128 & $34.2 \%$ & 130 & $34.6 \%$ \\
\hline Total & 374 & $100 \%$ & 376 & $100 \%$ \\
\hline $\mathrm{X}^{2}=10$ & \multicolumn{3}{c}{ D f $=1$} & $(\mathrm{p}=0.49)$
\end{tabular}

Table 3: Relative Frequency Distribution Hyperactivity of Grade Students in the City of Turpentine.

\begin{tabular}{|c|c|c|c|c|c|c|c|c|c|c|}
\hline \multirow{2}{*}{$\begin{array}{c}\text { Grade } \\
\text { Hyperactivity }\end{array}$} & \multicolumn{2}{|c|}{ First } & \multicolumn{2}{|c|}{ Second } & \multicolumn{2}{|c|}{ Third } & \multicolumn{2}{|c|}{ Fourth } & \multicolumn{2}{|r|}{ Fifth } \\
\hline & No & $\%$ & No & $\%$ & No & $\%$ & No & $\%$ & No & $\%$ \\
\hline No & 107 & $70.9 \%$ & 85 & $56.3 \%$ & 101 & $67.8 \%$ & 95 & $62.5 \%$ & 104 & $70.7 \%$ \\
\hline Yes & 44 & $29.1 \%$ & 66 & $43.7 \%$ & 48 & $32.2 \%$ & 57 & $37.5 \%$ & 43 & $29.3 \%$ \\
\hline Total & 151 & $100 \%$ & 151 & $100 \%$ & 149 & $100 \%$ & 152 & $100 \%$ & 147 & $100 \%$ \\
\hline
\end{tabular}

According to information obtained from second-grade $(43.7 \%)$, and grade four students $(37.5 \%)$, they had higher levels of hyperactivity than the others. Chi-square test 
Shows a significant correlation exists between the prevalence of hyperactivity and grade $(p=0.035)$.

More students hyperactivity $(60 \%)$ had an acceptable education (in terms of standards of education), the prevalence of ADHD and academic status were significantly related.

Results showed that none of the students participating in the study, living with one parent (father or mother) had a hyperactivity disorder, while the highest prevalence of ADHD was found in children who lived in families with more than six people (44\%). However, the prevalence of hyperactivity disorder in children based on a chi-square test showed that there was no significant correlation between the prevalence of hyperactivity and the number of family members $(p=0.16)$. In $41.6 \%$ of students, hyperactivity disorder was found in children of fathers who were Manual Laborers. The students whose father's occupation were ordinary employees were observed to have lower levels of hyperactivity. The prevalence of hyperactivity disorder in children based on a chi-square test showed a significant correlation between the prevalence of hyperactivity and the father's occupation ( $p=$ 0.006).

The lowest prevalence of ADHD was found in students whose mothers were employed. The prevalence of hyperactivity disorder in children based on a chi-square test showed that there was no significant correlation between the prevalence of hyperactivity and the mother's occupation ( $p$ $=0.47$ ). Students whose fathers had no education or only a primary education had higher levels of attention-deficit/hyperactivity disorder than the other students $(41.1 \%)$. The lowest percentages of students with ADHD had fathers who were high school graduates.
The prevalence of hyperactivity disorder in children based on a chi-square test showed a statistically significant difference between hyperactivity and parent's education ( $p=$ 0.037) Results also indicated that students whose mothers had no education or only a primary school education had the highest percentage of hyperactivity $(39.8 \%)$, whereas students whose mother's education was secondary school had the lowest prevalence of hyperactivity (23.2\%). Furthermore, based on a chi-square test it was demonstrated that the prevalence of hyperactivity and parent education was statistically significant $(p=$ 0.001).

\section{Discussion and conclusion}

The results of this research indicate that the prevalence of hyperactivity in elementary school children in Saghez City was $34.4 \%$. This prevalence rate, compared with other studies conducted in the city, is high. A research study conducted by Khobazkhob et al. Neyshabur has been reported to be $12.5 \%$ [3]. In addition, in another study that was conducted in Iranian schools nationwide, the prevalence of this condition was $8.5 \%$ [4].

The results of this study also show that the disorder is found equally in both boys and girls, and there was no significant correlation between gender and ADHD. However, a study by Araby et al. in Tehran [6] and Shirin Moradi et al. showed that levels of hyperactivity disorder were higher in boys (with a prevalence of 3\%) than among girls (with an incidence of $3.1 \%$ ) [10].

In total, more students $(5.46 \%)$ with ADHD were found in third and fourth children of the family. While few of the students who were the first child had hyperactivity disorder. In this regard, a study was carried out in Zanjan which was consistent with our study, they also found that 
hyperactivity disorder in one-child families (with $1.5 \%$ ) was less than in six member families (with $7.5 \%$ ) which had the highest levels [8].

The results of this study indicate that the prevalence of ADHD and academic status was statistically significant, there is so much more active students were in good academic. A study by the Ministry of Education to evaluate student took most of the students were more active in the education levels of acceptable_In case of students with good academic status of students is less hyperactive [10]._During a survey by the Araby, and colleagues with poor concentration disorders, hyperactivity families living in the settlement enterprise in Tehran was. Most of the students are more active in educational standards for educations are good [6].

Students with ADHD cannot be compared to a baseline, therefore the highest levels of hyperactivity were related to second-grade students $(43.7 \%)$. The disorder in the first and fifth-grade students had lower ratios. Contrary to this study, a survey by Moradi et al., conducted in relation to the prevalence of hyperactivity disorders suggested that the prevalence may be higher in first-grade students [10].

The prevalence of ADHD and family size were found to have no statistically significant differences. Although the prevalence is higher in larger families, and $44 \%$ of students who live in households with more than six people with ADHD are hyperactive. While the students who have family members or number of children in families with 5-3 members and 1 to 3 children, hyperactivity is less common. A study conducted in Tehran by Araby et al. suggested that hyperactivity in children is higher in large families [6].

The study findings show that there is a relationship between father's occupation and the prevalence of hyperactivity. Low-income families with jobs such as manual workers had the most children diagnosed with hyperactivity disorder. In addition, hyperactivity disorder in children who have been deprived of the blessed parents of students who have more than Dad can be seen._Similar results have been found in other studies. A study carried out by Moradi et al. showed hyperactivity in children, that his parents was workers is high [10]. A study conducted by Mehrangiz and Yusefy showed that fathers who have Manual labors or who are unemployed are more likely to be diagnosed with hyperactivity disorder [4]. In total $83.3 \%$ of students who have been deprived of a father's, and $6.41 \%$ of students who have working fathers may develop hyperactivity disorder. In the students who employees free of their father's job with a regular income of less than hyperactivity in children has been observed.

The results showed that $50 \%$ of students who have been deprived of the blessing of the mother (Mother lost) and the lowest prevalence of hyperactivity disorder ADHD was related to students whose mothers were employed.

Besides the relationship between the father and hyperactivity, in examining the relationship between maternal employment and hyperactivity, findings showed hyperactivity in a high percentage of students who have been deprived of the blessing of the mother, the children whose mothers were housewives had more hyperactivity disorders. Moradi et al. showed in a study of students whose mothers were housewives that ADHD is more prevalent [10].

In this study, the more active, the more often students $(40 \%)$ had parents who were illiterate or had only a primary level of education, and there was a significant correlation between the prevalence of 
hyperactivity and parents' education. Similar to this study, research conducted by Moradi et al. has suggested that in children with hyperactivity disorder, most of their parents are illiterate and have an elementary education

[10].

The results of this research indicated a high Prevalence of ADHD Saghez City in comparison with other regions of the country. Hyperactivity disorder in children who are living in economic and cultural poverty is higher, so that students with ADHD are more likely to have parents who were illiterate and only have a grade education. Fathers, who have regular jobs as low-income workers, are more likely to have hyperactive children. Families with more children also increased the likelihood of ADHD, which is a risk factor for families. Children who were the third and fourth child in the family suffered from this disorder more frequently. Often Hyperactive students are an acceptable academic status.

\section{Acknowledgements}

We would like to thank Dr. Koorosh Kamali, and Dr. Giti Karimkhanluei and all those who helped us to complete this project.

\section{References}

1. Alizadeh H. Theoretical Explanation of Attention Deficit Disorder - ADHD and the Nature of Self-Control Model of Behavioral Inhibition. Research on Exceptional Children. 2005; 3: 323-348.

2. Shabani M, Yadgari, A. Prevalence of Attention Deficit Hyperactivity Disorder (ADHD) in Elementary School Children in Zanjan 2004 -2005. J Zanjan Univ Med Sci. 2005; 13 (51):42-8.
3. Moradi, A, Khobazkhob M. Hyperactivity Disorder (ADHD) among School Children of Nishaboor - Iran during 2006. J Gorgan Univ Med Sci. 2008; 10 (2): 37-42.

4. Shahim S, Mehrangiz L, Yousefi F. Prevalence of Attention Deficit Hyperactivity Disorder in a Group of Elementary School Children. Iran J Pediatr. [Online] 2007: 211216.

5. Arabgol F, Haiati M, Hadid M. The Prevalence of Attention Deficit Hyperactivity Disorder in a Group of Students, Imam Hussein. Of Psychiatry. New Cognitive Sci. 2004; 21: 73-78.

6. Arabi N, Shafighi F, Gharahkhani S. The Study Prevalence of Attention-Deficit Hyperactivity Disorder (ADHD) in Iranian army Families Children who live in Military Town Tehran in 2006. HBI J. 2010; 8 (3): 179-185.

7. McGoey KE, Eckert TL, Dupaul GJ. Early Intervention for Preschool-Age Children with ADHD A Literature Review. J Emotional and Behavioral Disorders. 2002; 10(1):14-28.

8. Shabani M, yadgari A, Prevalence of Attention Deficit Hyperactivity Disorder in Primary School Children in Zanjan. J Zanjan Univ Med Sci. 2005; 51: 42- 48.

9. Dadkhahipur M. ADHD and the Role of Nutrition. www.aftabir.com .

10. Salehi B, Moradi S, Ebrahimi S, Rafeei M. Comparison of ADHD (Attention Deficit Hyperactivity Disorder) prevalence between Female and Male Students of Primary Schools in Arak City in Academic Year of 202009-2010. J Kurdistan Univ Med Sci. 2011; 16(2): 45-54. 